\title{
CATCHMENT SCALE HYDROLOGICAL MODELLING: A REVIEW OF MODEL TYPES, CALIBRATION APPROACHES AND UNCERTAINTY ANALYSIS METHODS IN THE CONTEXT OF RECENT DEVELOPMENTS IN TECHNOLOGY AND APPLICATIONS
}

\author{
I.G. PECHLIVANIDIS ${ }^{1^{*}}$ \\ B.M. JACKSON ${ }^{1}$ \\ N.R. MCINTYRE ${ }^{2}$ \\ H.S. WHEATER ${ }^{2,3}$
}

\author{
${ }^{1}$ School of Geography, Environment and Earth Sciences \\ Victoria University of Wellington \\ Kelburn, Wellington, New Zealand \\ ${ }^{2}$ Department of Civil and Environmental Engineering \\ ${ }^{3}$ School of Environment and Sustainability, \\ University of Saskatchewan \\ Saskatoon, S7N 5C8, Canada
}

Received: 23/12/10

Accepted: $17 / 06 / 11$ *to whom all correspondence should be addressed: e-mail: ilias.pechlivanidis@vuw.ac.nz (or @gmail.com)

\begin{abstract}
ABSTACT
In catchment hydrology, it is in practice impossible to measure everything we would like to know about the hydrological system, mainly due to high catchment heterogeneity and the limitations of measurement techniques. These limitations and the need to extrapolate information from the available measurements in both space and time initiated the application of hydrological models. However, hydrological models suffer from uncertainty in their predictions, which reduces applicability of and confidence in such models. In this review, we summarise the different classifications of hydrological model types, and discuss relative advantages and disadvantages of each type of model. In addition, we summarise established model calibration processes and discuss the sources of uncertainty that affect model predictions. We summarise different methods to quantify uncertainty in the model predictions that could sit well within a model evaluation framework. And, finally, some recent developments in hydrological modelling are reviewed.
\end{abstract}

KEYWORDS: Hydrological models; Model identification; Calibration; Uncertainty; Sensitivity analysis.

\section{INTRODUCTION}

Hydrological models are important for a wide range of applications, including water resources planning, development and management, flood prediction and design, and coupled systems modelling including, for example, water quality, hydro-ecology and climate. However, due to resource constraints and the limited range of available measurement techniques, there are limitations to the availability of spatial-temporal data; hence a need exists to extrapolate information from the available measurements in space and time; in addition there is a need to assess the likely hydrological impact of future system response, for example to climate and land management change.

Hydrological model applications have a variety of objectives, depending on the problem that needs to be investigated. Singh and Woolhiser (2002), among others, summarised the different aims of hydrological modelling:

- Extrapolation of point measurements in both space and time.

- Improving the fundamental understanding of existing hydrological systems and assessing the impact of change (e.g. climate and land cover change) on water resources. 
- Developing new models or improving old models for management decisions on current and future catchment hydrology (e.g. water-table management, wetland restoration, irrigation water management, streamflow restoration, water quality evaluation, and flood forecasting and management).

There are several published reviews of hydrological modelling (e.g. Wheater et al., 1993; Beven, 2001; Singh and Woolhiser, 2002; Wagener et al., 2004), however some aspects of the field are changing rapidly, for example new developments in distributed modelling, treatment of uncertainty, modelling ungauged basins and non-stationarity; hence there is now scope for an updated review of modelling capabilities and limitations. The paper is organised as follows. Section 2 gives a review of the different model types. Section 3 presents model identification methods with emphasis on model calibration and sensitivity analysis. Section 4 presents uncertainty analysis methods, highlighting the different sources of uncertainty and methods to quantify their importance in model predictions. Section 5 presents recent developments in hydrological modelling, including distributing modelling and use of remote sensed data, Prediction in Ungauged Basins, and integration of land surface schemes into Global Climate Models. Finally, Section 6 consists of a discussion and summary.

\section{CLASSIFICATION OF HYDROLOGICAL MODELS}

Previous reviews have outlined several ways to classify hydrological models (see for example, Singh, 1995; Singh and Frevert, 2006). In the current paper, we follow the classification system outlined in Wheater et al. (1993); hence, models are classified based on their model structure, spatial distribution, stochasticity, and spatial-temporal application.

\subsection{Model structure based classification}

\subsubsection{Metric models}

The essential characteristic of metric models is that they are primarily based on observations and seek to characterise the system response from the available data (Wheater et al., 1993). Metric approaches are thus essentially empirical; an early example is unit hydrograph (UH) theory for event-based catchment-scale simulation developed by Sherman (1932). The simplicity of such models has allowed them to be applied relatively easily to ungauged catchments by regional analysis, relating (parsimonious) model properties (i.e. unit hydrograph time to peak, percentage runoff etc.) to physical and climatic descriptors of the catchment. This type of regional analysis was developed for national application in the UK Flood Studies Report (NERC, 1975) and Flood Estimation Handbook (NERC, 1999), for example. However, it should be noted that metric models depend on the range of available data and although they have been used to extrapolate to extreme events or ungauged catchments, results are usually lacking in formal specification of confidence limits (Wheater, 2002).

Among the most interesting of recent approaches in metric modelling are Data Based Mechanistic (DBM) modelling (Young et al., 1997; Young, 2003; Ratto et al., 2007) and Artificial Neural Networks (ANN) (Lange, 1999; Jain et al., 2004; Dawson et al., 2006). ANNs use available rainfall and runoff data to learn about the behaviour of rainfall-runoff processes. ANNs generally have three layers: the first layer is the layer of input (i.e. rainfall), the second layer is the hidden layer of neurons, and the third layer is the layer of output (i.e. streamflow). This type of model learns the relationship (a process usually called "training") between input and output by adjusting the connection weights in the network so that the network response closely matches the runoff response (Lekkas, 2008).

DBM modelling draws on a powerful family of methods for time-series analysis and simulation. It is an empirical approach whereby the model structure is developed as an empirical transfer function model based on the available input-output data (Young, 2005); hence parameters can be estimated from input-output data only. The model is further evaluated and interpreted in a physically meaningful, mechanistic manner, which differs from a purely empirical approach (Lees, 2000). Generally, the identified transfer function model is defined as a combination of a non-linear filter (to generate effective rainfall) followed by linear stores to represent the hydrological responses, such as "quick" and "slow" flow processes (Young, 1999; Lekkas and Onof, 2006). An advantage of the DBM method is its ability to identify structures without being constrained by prior hypotheses, and hence the ability to identify models which were unexpected a priori (Mclntyre et al., In Press). 


\subsubsection{Conceptual models}

According to Wheater et al. (1993), conceptual models are based on two criteria: firstly, the structure of the model is specified prior to any modelling being undertaken, and secondly not all of the model parameters have a direct physical interpretation (i.e. they are not independently measurable). Therefore at least some conceptual model parameters have to be estimated through calibration against observed data. Conceptual models generally represent all of the component hydrological processes perceived to be of importance in catchment scale input-output relationships (Wheater, 2002). This type of model varies considerably in complexity and the model structure tends to be based on extensive use of schematic storages, which are combined to represent a conceptual view of the important hydrological features. Models can vary in complexity from two or three simple storages up to a highly complex representation. Wheater (2002) noted that "a simple model structure does not reflect the complexity of the rainfall-runoff response and a complex model structure is not always supported by the available data. A balance between the complexity of the model and available information is crucial for successful model identification". Model complexity can be reduced by an appropriate degree through identification statistics (Dunn et al., 2008) or sensitivity analysis (Fenicia et al., 2008; van Werkhoven et al., 2009), and by holding insensitive parameters constant or formally re-structuring the model (Mclntyre and Al-Qurashi, 2009).

\subsubsection{Physics-based models}

Physic-based models represent the component hydrological processes such as evapotranspiration, infiltration, overflow, and saturated and unsaturated zone flow using the governing equations of motion (usually formulated as non-linear partial differential equations) based on continuum mechanics. Generally, the equations of motion of the constituent processes are solved numerically using a finite difference or a finite element spatial discretisation; however, analytical solutions can exist (Wheater et al., 1993). In theory, physics-based models are defined by wholly measureable parameters and can provide continuous simulation of the runoff response without calibration (Beven, 2001). Such models are a powerful compilation of the relevant idealised processes but raise a number of important issues.

The physics behind the model structure are generally based on laboratory or small-scale in-situ field experiments, and hence are affected by the nature of the experiments themselves. Extrapolation to larger (e.g. catchment) scales often involves the assumption that the physical processes and properties are independent of scale, raising uncertainty about their applicability (Beven, 2004). To reduce computational burden and data requirements, simplified physics/mechanics are sometimes used to represent the physics (e.g. simplified St. Venant equations, the Green-Ampt equation [Green and Ampt, 1911; Mein and Larson, 1973)], leading to deviation from the physical basis and additional questionability.

Catchments typically have a high level of spatial heterogeneity which can be prohibitively expensive to observe or comprehensively represent in the model. This is most obvious in the representation of subsurface processes because of the difficulty of observation and the high degree of soil/aquifer heterogeneity which often exists. In principle the parameters of physics-based models are measurable, but in practice this cannot be achieved at the scale of modelling application, because such measurements are essentially made at a point (Wheater, 2002). Therefore, these models use averaged variables and parameters at grid or element scales which are greater than the scale of variation of the processes. Even under a "full" physics representation, parameterisation (including spatial variability of parameters) of material properties does not represent catchment heterogeneity. The values of local scale properties can be estimated (generalised soil descriptions such as the NSRI database (Hallett et al., 2006) and/or through a calibration procedure) but the uncertainties are sufficiently large that they may encompass a wide range of process responses (e.g. Stephenson and Freeze, 1974).

\subsubsection{Hybrid models}

Many models are labelled as one of the above types but in truth include elements of two or more. Hybrid metric-conceptual models have been developed to combine the strengths of data-based and conceptual models. They commonly consist of a simple conceptual loss function (i.e. soil moisture accounting module to produce effective rainfall) and a simple routing component (i.e. a routing module to transfer the effective rainfall to streamflow) (Wagener, 2002). These models offer scope 
for dealing with problems associated with lack of parameter identifiability [e.g. the problem of equifinality described by Beven (2006)] through reduction of the dimensionality of the parameter space. Hybrid models take advantage of: 1) the unique parameterisation of metric models and their ability to efficiently characterise the observational data in statistical terms, and 2) other prior knowledge to test hypotheses about the structure of component hydrological stores. Many so-called physics-based models are in fact hybrid physically-based-conceptual models [e.g. SWAT (Arnold et al., 1993)]. These aim to simplify model structure by representing some of the mathematical-physics based processes in a conceptual manner, particularly in cases where physical parameters are difficult to measure. In principle this may lead to some improvement in parameter identifiability, although such models often have very high dimensionality of the parameter space. And models which are primarily conceptual can introduce physically-based components in an attempt to reduce the calibration load [e.g. a hydrodynamic channel model driven by outputs of a conceptual hillslope model such as in Ajami et al. (2004)].

\subsection{Other types of classification}

\subsubsection{Lumped and distributed models}

Lumped models treat the catchment as a single unit, with state variables that represent averages over the catchment area (Beven, 2001). In general a lumped model is expressed by differential or empirical algebraic equations, taking no account of spatial variability of processes, inputs, boundary conditions and system (catchment) geometric characteristics (Singh, 1995). Distributed models make predictions that are distributed in space, with state variables that represent local averages, by discretising the catchment into a number of elements (or grid squares) and solving the equations for the state variables associated with every element (Singh and Frevert, 2006). Distributed models hence are capable to some extent of taking into account spatial variability in processes, inputs, boundary conditions, and catchment characteristics. However, all distributed models use average variables and parameters at element or grid scales, and often parameters are averaged over many grid squares, mainly due to data availability (Beven, 2001).

Semi-distributed models have been suggested to combine the advantages of both types of spatial representation. This type of model does not pretend to represent a spatially continuous distribution of state variables; rather it discretises the catchment to a degree thought to be useful by the modeller using a set of lumped models. A semi-distributed model can therefore represent the important features of catchment, while at the same time requiring less data and lower computational costs than distributed models (Orellana et al., 2008).

\subsubsection{Deterministic and stochastic models}

Models can be classified as deterministic when the results are uniquely determined through known relationships between the states and data. Deterministic models produce a single result from a simulation with a single set of input data and parameter values, and a given input will always produce the same output, if the parameter values are kept constant. Stochastic models use random variables to represent process uncertainty and generate different results from one set of input data and parameter values when they run under "externally seen" identical conditions (Beven, 2001). A particular set of inputs will produce an output according to a statistical distribution. This allows some randomness or uncertainty in the possible outcome due to uncertainty in input variables, boundary conditions or model parameters. Mixed deterministic-stochastic models can also be created by introducing stochastic error models to the deterministic model. For example, stochastic rainfall could be used as an input to a deterministic rainfall-runoff model (Singh, 1995); or a deterministic model may be used to represent a stochastic system using Monte Carlo simulation (see Section 4.2).

\subsubsection{Time-scale based classification}

Rainfall-runoff models can be classified as continuous simulation models or event based models. Continuous simulation typically would take into account a time series of rainfall, which may incorporate more than one storm event, while event-based models take into account only one storm event. Singh (1995) explained that the time scale may be defined by the time intervals used for input and internal computations, or by those used for output and calibration of the model, and the choice is usually a function of the model's intended use. Thus, other sub-classifications of the continuous time based models are distinguished: sub-daily, daily, monthly, and yearly models. 


\subsubsection{Space-scale based classification}

According to Singh (1995) models may be classified into those of small catchments (up to $100 \mathrm{~km}^{2}$ ), medium-size catchments $\left(100-1000 \mathrm{~km}^{2}\right.$ ), and large catchments (greater than $1000 \mathrm{~km}^{2}$ ). However this classification is arbitrary and not conceptual, and more ideally the classification might be based on homogeneity, for example the scale at which processes can reasonably be averaged, i.e. the hydrological response unit size (Young et al., 2006; Wagener et al., 2007).

\section{IDENTIFICATION OF HYDROLOGICAL MODELS}

\subsection{Calibration of hydrological models}

Model calibration is the process of selecting suitable values of model parameters such that the hydrological behaviour of the catchment can be simulated closely (Wagener et al., 2004; Moore and Doherty, 2005). There are two types of model parameters in most models: physical parameters, and process parameters (Sorooshian and Gupta, 1995). Physical parameters represent the physical properties of the catchment and are usually measurable, such as the catchment area, surface slope etc. Process parameters represent catchment characteristics that cannot normally be measured such as the average depth of water storage capacity, coefficient of nonlinearity controlling discharge rates from component stores, etc. (Sorooshian and Gupta, 1995). There are some physical parameters, such as the hydraulic conductivity and porosity, which are measurable in theory but difficult to measure in practice, and hence are often calibrated. The calibration process can be either manual or automatic; however in practice is often a combination of the two.

\subsubsection{Manual calibration}

This is a process that mainly depends on the modeller adjusting "by hand" model parameter values until the output of the model closely matches the observed data. The adjustment of the parameter values is made by the modeller by a trial and error process, so familiarity with the model structure and the study catchments saves time and effort. In general, it is difficult to determine the "best fit" or to determine a clear point indicating the end of the calibration process, and hence different results will be obtained by different modellers (Wheater, 2002). The time consuming nature is another problem with this type of calibration. The whole procedure could provide no or limited information from the previous parameter adjustments and a formal analysis of uncertainty is "difficult to impossible" (Sorooshian and Gupta, 1995).

\subsubsection{Automatic calibration}

The development of computer-based methods for automatic calibration of hydrological models has been partly motivated by the need to speed up (in terms of computational efficiency) the process of calibration. Another aim has been to develop an objective strategy for parameter estimation that provides consistent performance by eliminating the subjective human judgement involved in the manual approach (Boyle et al., 2000). The automatic process can provide more objectivity and reduce the need for expertise with the particular model (Sorooshian and Gupta, 1995). However, automatic calibration methods have not yet matured to the point that they can entirely replace manual methods due to the difficulty of constructing objective functions and optimisation algorithms (see below) which replicate human judgement; and hence automatic calibration is often most successful when used in conjunction with a manual procedure.

According to Sorooshian and Gupta (1995) a typical automatic parameter estimation procedure consists of four major elements: the selected objective function (or performance measure), the optimisation algorithm, the termination criteria, and the calibration data. The authors stated that the purpose of the automatic calibration is to find those values of the model parameters that optimise (minimise or maximise, as appropriate) the numerical value of the objective function.

\subsubsection{Objective functions (OFs)}

An objective function (or goodness of fit) is a numerical measure of the difference between the model simulated output and the observed (measured) catchment output (Schaefli and Gupta, 2007). Many different objective functions can be found in the literature; however the most common 
objective functions are based on the standard least squares methods (and equivalent methods) and maximum likelihood methods.

Drawing from statistical regression and model-fitting theory, the most commonly used objective function has been some form of the Weighted Least Squares (WLS) function (Croke, 2007). The objective function may include weight parameters, which indicate the importance to be given to fitting particular hydrograph characteristics. Among others, Croke (2007) and Koren et al. (2008) suggested that including additional data sources, such as soil moisture and groundwater level data, can improve the consistency and stability of the parameter estimates.

A popular objective function in the hydrological literature is the Nash-Sutcliffe Efficiency, NSE, criterion, which gives the proportion of the variance of the data explained by the model (Nash and Sutcliffe, 1970). Recent studies show that NSE is able to capture the time to peak and linear correlation with observed flow while underestimating the variability and mean of flows (Schaefli and Gupta, 2007; Gupta et al., 2009, Pechlivanidis et al., 2010a). The recently proposed measure called Kling and Gupta Efficiency, KGE (Gupta et al., 2009) has been introduced to overcome some limitations of NSE. In the few studies to date, KGE seems to be able to match well variability, peak and mean of flows, while keeping the linear correlation between modelled and observed data high (Pechlivanidis et al., 2010a).

Sorooshian and Dracup (1980) developed Maximum Likelihood based objective functions to more rigorously account for the presence of either autocorrelation (non-independence) or heteroscedasticity (changing variance) of the streamflow data errors. However in general this type of formal likelihood function is not favoured in hydrology because the implicit assumptions about data and model errors are not justifiable, except in studies using synthetic data sets (Beven, 2001). Other functions which are more intuitive to hydrologists, such as NSE or KGE, are generally preferred.

\subsubsection{Multi-objective analysis}

Generally, results based on single objective functions are biased to individual aspects of the hydrograph; hence intelligent selection of objective functions for specific modelling tasks (e.g. flood forecasting, design irrigation schemes, hydroelectric power generation) is crucial (Yapo et al., 1998). A parameter set that is optimal for one criterion is rarely that which would be gained using a different criterion, while if tradeoffs between several criteria are necessary to satisfy conflicting objectives, an optimal parameter set becomes hard to define (Beven, 2001). To address this type of limitation, the multi-objective approach, which can consider different aspects of model performance simultaneously, was introduced. The results can be used to illustrate the limitations of the model with respect to its inability to simultaneously achieve different performance objectives; and can allow the modeller to choose the performance trade-off which best suits the application (Gupta et al., 2005).

One common approach is to aggregate the multi-objectives into a single objective criterion and optimise to the single-valued best fit. The result is then strongly dependent on the aggregation, or weighting of the objectives (Yapo et al., 1998). An alternative is to employ the concept of Pareto optimality, in which a Pareto set of solutions is generated with the characteristic that moving from one solution to another results in the improvement of one criterion while causing deterioration in one or more others (Boyle et al., 2001). According to Gupta et al. (1998), the Pareto set represents the minimum uncertainty that can be achieved for the parameters via calibration, without subjectively assigning relative weights to the individual model responses. This uncertainty arises due to limitations of the model structure; and the degree of trade-offs between objective functions and associated variability of parameter values can be used to help identify and characterise model structural error (Wagener et al., 2003; Lee et al., 2005).

\subsubsection{Optimisation algorithms}

The surface described by the objective function in the parameter space is called the response surface. The optimisation algorithm searches the response surface for the parameter values that optimise (minimise or maximise) the numerical value of the objective function, constrained to the pre-defined allowable ranges of the parameters. Most optimisation methods or strategies can be classified as either local search methods or global search methods.

Local search methods are designed to efficiently find the local minimum (or maximum) of a response surface (or over some small neighbourhood). These type of methods seek to continuously proceed 
in the direction of improving function value to eventually arrive at the location of the function optimum, irrespective of where in the parameter space the search procedure started (Sorooshian and Gupta, 1995). The procedure involves three main steps: selecting the direction to move in parameter space, deciding how far to move in that direction, and deciding on the termination time when no further improvement is considered possible. Local search methods may be classified as direct search methods and gradient methods. The former includes straightforward interval searches, the downhill simplex and rotating directions are considered as direct search methods. Gradient methods include methodologies as the steepest descent, the conjugate gradient, the NewtonRaphson method, quasi-Newton/variable metric methods and the Levenburg-Marquadt method (Jackson, 2007).

Using a local search, we assume that the solution exists at the first point in the response surface where the slope is found to be zero within some specified tolerance, minimising (or maximising) the objective function value. However, recognising that there may be multiple points with near-zero slopes, this is not normally alone an adequate criterion. Hence global search methods explore the entire feasible region of the parameter space attempting to find the bottom of the deepest valley. This type of method generally involve the evaluation of the objective function at a random sample of points in the feasible parameter space, followed by subsequent manipulations of the sample using a combination of deterministic and probabilistic rules (Jackson, 2007).

Random search methods are broadly used in hydrological modelling. Sets of random values are generated from a specified distribution of model parameters, which are then substituted into the model equations to obtain corresponding sets of outputs. In the absence of prior information on joint probabilities, the specified distribution commonly assumes that the parameters are independent (Beven, 2009). Other global optimisation methodologies include set covering techniques, pure random search, adaptive and controller random search, multiple local search, simulated annealing, and tabu search. Evolutionary and genetic algorithms such as Multi-Objective COMplex evolution (MOCOM) (Yapo et al., 1998), Shuffled Complex Evolution (SCE) (Duan et al., 1993), MultiObjective Shuffled Complex Evolution Metropolis (MOSCEM-UA) (Vrugt et al., 2003), AMALGAM (Vrugt et al., 2008a), and DREAM (Vrugt et al., 2008b) have been used in hydrological applications.

\subsubsection{Termination criteria}

There are three main ways to terminate the search: objective function convergence, parameter convergence, and maximum number of iterations. Based on the function convergence criterion the iterations are terminated when the function value cannot be significantly further improved. The parameter convergence is used to stop the searching when the algorithm is unable to significantly improve the parameter values and thus, cannot improve the function over one or more iterations. Finally, the maximum iteration criterion is used as a backup to prevent waste of computer time, by determining the maximum number of iterations.

\subsubsection{Verification}

Verification (also known as validation) takes place after calibration to test if the model performs well on a portion of data, which was not used in calibration. Model verification aims to validate the model's robustness and ability to describe the catchment's hydrological response, and further detect any biases in the calibrated parameters (Gupta et al., 2005). Model performance is usually better during calibration than verification period, a phenomenon called model divergence (Sorooshian and Gupta, 1995). When the degree of divergence is considered unacceptable, modeller has to examine the model structure and the calibration procedure for valid or inappropriate assumptions and then revise accordingly.

Split sample tests have commonly been tried [see Perrin et al. (2001)], where one period of observations is used in model calibration and one or more separate periods are used to check that the model predictions are satisfactory. Klemes (1986) proposed tests including different split sampling tests, proxy catchment testing and proxy catchment split sample tests. A proxy catchment is treated as ungauged at the model estimation stage, but with some observations of discharge and perhaps other variables which are available for the evaluation of the model predictions. More recently, Ewen and Parkin (1996) and as an extension Bathurst et al. (2004) proposed the following tests: 
- Simple split-sample test.

- Different split-sample test, where the data is divided according to rainfall rate (or some other variable) in an attempt to show that the model has some general validity.

- Proxy-catchment test, which uses data for two catchments. This test can be used to show the model has even greater general validity as it involves calibrating the model against data for one catchment and then running a validation test using data for the other catchment.

- Different proxy-catchment testing, where the observed data for each catchment are divided into two sets according to the rainfall rate (or some other variables). Then the model is calibrated against one of the sets (e.g. the dry period for the first test catchments) and a validation test is run using a contrasting set (e.g. the wet period data for the second catchment).

\subsection{Sensitivity analysis}

According to Sorooshian et al. (1995), sensitivity analysis evaluates the impact of changes in the model parameters, inputs or (initial) states on the model output of interest. The region around the best parameters estimates, in which the function value varies from the best function value by only a small value, is called the region of indifference. Sensitivity analysis can determine if there is dependence among parameters, if two or more parameters are simultaneously changed. Wagener and Kollat (2007) stated that any sensitivity analysis can be broken up into two components: investigation of the model parameter space, and a numerical or visual measure of the impacts of sampled parameters on the model output of interest. Various examples can be found in Beven (2009) and Matott et al. (2009).

There are two types of sensitivity analysis: local sensitivity analysis and global sensitivity analysis. The former type of analysis aims to assess the impact of change in the parameter values within the local region of indifference on the model output. The local nature of this type of sensitivity analysis inherently limits its ability to identify all potentially relevant features of the response surface. However, local sensitivity analysis methods are useful when interested in the local region of indifference while saving computational effort. The nominal range and differential analysis methods (Helton and Davis, 2003) are two local sensitivity analysis methods.

Alternatively, global sensitivity analysis attempts to explore the full parameter space within predefined feasible parameter ranges (Tang et al., 2007). A statistic is used to measure the general variability of the objective function over the space, or a sub-dimension of the space. For example, this may be a measure of how the response surface deviates from a uniform value of the objective function, for instance using the Kolmogorov-Smirnov test (Mclntyre et al., 2005a). The literature identifies a variety of global sensitivity analysis methods such as regional sensitivity analysis (Hornberger and Spear, 1981), variance based methods (Saltelli, 2002), regression based approached (Helton and Davis, 2002), and Bayesian sensitivity analysis (Freer et al., 1996; Vrugt and Robinson, 2007).

Most sensitivity analyses consider only univariate or bivariate (first-order interactions) effects on model response. Despite the difficulty, especially where many factors are being considered, highorder interactions could be analysed; however, additional computational effort and analytical complexity is required (Saltelli, 2002).

A powerful extension of sensitivity analysis is to evaluate the dynamic sensitivity of model parameters, for example by evaluating sensitivity based on a moving window passed through the observed and simulated time-series. Such a procedure was developed by Wagener at al. (2004), known as DYNIA. This can be used to identify, for example, periods within an observed time-series for which specific parameters are sensitive, and hence the time-varying information content of data, and also can reveal tensions within a model structure - for example, where parameters tend to different optimal values at different points in time.

\section{UNCERTAINTY ESTIMATION}

Singh (1995) stated that uncertainty analysis is the means of calculating and representing the certainty with which the model results represent reality; hence uncertainty analysis examines the meta-effect of specific model uncertainties. The generation of quantitative measures of confidence in a model's results is essential for providing guidance about the weight which should be given to the 
model in decision making, and for indicating where the model may need to be improved. According to Melching and Singh (1995), confidence intervals are used to define ranges (e.g. 95\%) within which the mean estimate will exist with specified probability. A second type of interval is the tolerance interval, which is defined as containing a certain proportion of the uncertain model estimates of an observation used in model calibration.

Information on model uncertainty is available from the normal process of automatic calibration and verification of a selected hydrologic model for a given catchment, and usually requires small additional effort on the part of the hydrological modeller. If a measure of belief is associated with each set of predictions, the resulting uncertainty in the predictions can be estimated in a conceptually very simple way by weighting the predictions of all the acceptable models by their associated degree of belief (e.g. resulting to single- or multi-model prediction ensembles). Such an approach allows the non-linearity of the response of acceptable models using different parameter sets to be taken into account in prediction and uncertainty estimation (Beven, 2009).

\subsection{Sources of uncertainty}

Estimating the total uncertainty inherent to a hydrological model involves the identification and quantification of four sources: natural uncertainties, data uncertainties, model parameter uncertainties, and model structure uncertainties.

\subsubsection{Natural uncertainties}

This describes the uncertainty arising from natural random effects which includes the random temporal and spatial fluctuation that always affects the physical process of runoff generation (Melching and Singh, 1995; Singh, 1997). The extent to which we can describe natural uncertainties depends on the quality and the type of available data for describing the random effects (Guo et al., 2004). For example, a dense rain gauge network or radar rainfall data, may allow much of the spatial randomness of rainfall to be observed and explicitly represented, reducing input uncertainty (and potentially therefore structural and parameter uncertainty). However, Beven (2009) stated that with hydrological systems it should not necessarily be expected that the consideration of additional data will decrease the uncertainty in the predictions.

\subsubsection{Data uncertainties}

The importance of uncertainty in the data (for instance, due to inadequate quality control) may depend on whether the model parameters are determined from calibration or from physical measurements and principles. For instance, Oudin et al., (2006) showed that systematic errors and uncertainties in rainfall data were transferred to the parameters of the model as bias in the parameters. However, the model performance using erroneous data and biased parameters may not greatly differ from that using true data and parameter values (Gourley and Vieux, 2006; Liu et al., 2009). The reason is that the calibration provides an adjustment factor able to compensate for errors and bias.

Rainfall spatial and temporal variability are basic reasons for uncertainty in precipitation data (Pechlivanidis et al., 2008; Vrugt et al., 2008c). Other model inputs such as evapotranspiration and catchment morphology data also affect uncertainty in model predictions (Dodov and FoufoulaGeorgiou, 2005; Gotzinger and Bardossy, 2008). In addition, uncertainty arises from the discretetime nature of the data, which provides no information about the variation within time steps which can affect parameter estimates (Kavetski and Clark, 2010a; 2010b).

\subsubsection{Model parameter uncertainties}

The use of limited data and uncertain data in calibration will lead to uncertainty in parameter estimates (Mclntyre et al. 2002). For instance, Ratto et al. (2001) and Freer et al. (2004), among others, showed that significant bias in observed data will inevitably lead to biased parameter estimates. Furthermore, common practice is to encompass the effective model structure uncertainty in parameter uncertainty (Huang and Liang, 2006; Ajami et al., 2007; Pechlivanidis et al., 2010b). However, there are many difficulties in obtaining unique and "conceptually" realistic parameter values by model calibration as was discussed by Sorooshian and Gupta (1995): irrespective of data and model structure uncertainty, over-parameterised models will have fundamental parameter 
equifinality (Beven and Freer, 2001). Through suitable uncertainty frameworks (see below), all these sources of uncertainty can be represented by joint distributions of parameters.

\subsubsection{Model structure uncertainties}

In hydrological applications, consideration of hydrological processes and their mathematical representations leads to the selection of a model structure. However, this structure is controlled by our understanding of the hydrological system, which is determined by the data available. Hence other unobserved processes are usually ignored, introducing uncertainties to modelling results. In general, uncertainties related to the model structure are identified through the model behaviour for runoff properties such as peak discharge, time to peak, runoff volume (Butts et al., 2004) or through time-series diagnostics (e.g. Wagener et al. 2003). The research community has recently emphasised the need for explicit identification of model structure uncertainty and diagnosis of differences in hydrological behaviour between model structures (Bai et al., 2009). Recent methods have focused on estimating the uncertain model structure via data assimilation frameworks (Liu and Gupta, 2007; Smith et al., 2008; Bulygina and Gupta, 2009; Mclntyre et al., In Press). For instance, Fenicia et al. (2008) proposed a methodology to systematically update the model structure, progressively incorporating new hypotheses of catchment behaviour.

\subsection{Methods for uncertainty estimation}

There are numerous methods for assessing uncertainty in hydrological models. These can fall into one of three categories: analytical methods, computer algebra based (black box) methods, and sampling based methods.

Analytical methods involve either the differentiation of model equations and solution of a set of auxiliary sensitivity equations, or the reformulation of the original model using stochastic algebraic/differential equations. Although analytical techniques are computationally efficient, severe assumptions are required as well as access to the underlying model equations and formulation (Isukapalli, 1999). Therefore they are not generally considered applicable.

The most commonly used methods for uncertainty estimation are sampling based strategies which require no access to model equations or even the model code, and only require the model outputs associated to a set of input/parameter combinations. Uncertainty is performed by executing the model repeatedly for sets of parameter values sampled from a probability distribution; however, these methods are computationally expensive.

Monte Carlo (MC) simulation is an extremely flexible and robust sampling based method widely used for uncertainty problems in hydrological applications (Beven, 2009). The uncertain parameters are described by probability distributions, and in the absence of information on joint probabilities, model parameters are assumed independent. Random values of each of the uncertain parameters are generated according to their respective probability distributions and the model is run using each random sample. Thereby, samples of model outputs are generated giving statistics (e.g. mean, standard deviation, skewness) and estimated probability distribution of the model output can be determined.

The main disadvantage of $\mathrm{MC}$ methods is that a great number of model runs are often required to reliably represent all probable results (and adequately describe the response surface), especially when there are a number of random variables. Although the adequate number of samples is case specific, in general the greater the number of parameters and the greater the complexity of the response surface, the greater the number of simulations that are required. Replication of MC sampling is useful to check convergence (McIntyre and Al-Qurashi, 2009).

A degree of computational efficiency can be accomplished through the use of efficient sampling methods which may include heuristic search procedures, or less informed approaches where segments of the probability distributions are split or stratified, and systematically explored (Jackson, 2007). For example, the stratified Latin Hypercube sampling method (Helton and Davis, 2003) divides the range of probable values for each parameter into ordered segments of equal probability and combines the individual samples to produce the parameter sets.

Many of the more promising heuristically guided sampling methods take advantage of Markov Chain Monte Carlo (MCMC) techniques (Kuczera and Parent, 1998; Smith et al., 2008). MCMC methods draw samples from probability distributions based on constructing a Markov chain that has the 
desired distribution as its equilibrium distribution (Vrugt et al., 2009). Each state is visited the required number of times to satisfy the conditional distribution of the parameters given the data and this is achieved through satisfying appropriate conditions of reversibility (detailed balance) and ergodicity (Hastings, 1970). A challenge in MCMC methods is to determine how many steps are needed to converge to the stationary distribution within an acceptable error. The most common application is numerically calculating multi-dimensional integrals, where an ensemble of sets moves around randomly (yet the samples are correlated). Some random walk MCMC methods are the Metropolis-Hastings algorithm, Gibbs sampling, Slice sampling, and Multiple-try Metropolis (Beven, 2009).

The validity of performing Monte Carlo (or Markov Chain) analysis is somewhat obscured due to the practical difficulty of adequately specifying the model parameter distribution in the presence of noise/error in the data; an erroneous selection of the distribution could influence the model results (Kavetski et al., 2006).

\subsection{Uncertainty analysis frameworks in hydrological modelling}

Uncertainty in hydrological modelling must consider three aspects: understanding, quantification, and reduction of uncertainty. To address this objective, increasing research effort has been devoted to moving towards more robust uncertainty frameworks. Among the first developed frameworks, the Generalised Likelihood Uncertainty Estimation (GLUE) (Beven and Binley, 1992) employs MC simulation as a key component and uses a likelihood measure (e.g. inverse of the error variance) to measure degree of acceptability of models, and degree of equifinality between models. This aims to avoid over-conditioning towards a single parameter set and the exclusion of parts of the model parameter space that might provide acceptable fits to the data and be useful in prediction. The main shortcoming of the GLUE procedure is the dependency of the uncertainty estimation on the selection of the value separating acceptable (behavioural) and unacceptable (non-behavioural) simulations based on a cut-off threshold. In addition, most applications of GLUE use an informal likelihood function which does not formally account for the number of measurements used to condition the parameter estimates (Mantovan and Todini, 2006). Although this is arguably counter-intuitive, it is applied to avoid over-conditioning and thus ensure that parameter uncertainty reflects total uncertainty (Vrugt et al., 2008c).

Other coherent methods for handling structure uncertainty are based on the concept of Bayesian model averaging (BMA) and multi-model ensemble method (MME). The BMA framework aims to jointly assess model structure and parameter uncertainties; however, it tends to be computationally demanding and also requires reliable prior information about model parameters. Instead of estimating the probability of each model as in a BMA framework, the goal of MME is to account for uncertainty by means of sampling from the output distributions of several different models (Liu and Gupta, 2007). Although several uncertainty analysis frameworks have been identified in the hydrological literature, (Thiemann et al., 2001; Vrugt et al., 2003; Wagener et al., 2004; Neuman, 2003; Vrugt et al., 2005; McIntyre et al., 2005b), few of these methods completely address the critical aspects of uncertainty analysis (data error, structure error and output error) in an explicit and cohesive way (Liu and Gupta, 2007).

Despite the challenges in dealing with multiple sources of uncertainty, few frameworks have been introduced to explicitly treat input, output and model structure uncertainty. Kavetski et al., (2006) introduced the BAyesian Total Error Analysis (BATEA) framework, which explicitly treats all sources of uncertainties and integrates these models into the posterior inference of model parameters and predictions. An Integrated Bayesian Uncertainty Estimator (IBUNE) framework was introduced by Ajami et al. (2007) combining Bayesian model combination techniques and a probabilistic parameter estimator algorithm to assess the integrated uncertainty propagation within a system.

Other frameworks have been introduced to diagnose differences between hydrological model structures. Clark et al. (2008) presented a Framework for Understanding Structural Errors (FUSE) to diagnose differences in hydrological model structures. FUSE uses unique model structures, developed by combining components of existing hydrological models, to quantify structural uncertainty in model simulations. More recently, Bai et al. (2009) introduced a top-down framework for model evaluation and selection under uncertainty. Models of different complexity were evaluated in an ensemble framework to capture the observed data signature and its variability. The framework uses a fuzzy rule system to select model structures by combining performance measures. 


\section{RECENT DEVELOPMENTS IN HYDROLOGICAL MODELLING}

In the past few years, the hydrologic community has devoted a considerable effort to understand existing hydrological systems in pursuit of more accurate and more powerful models. Particular emphasis was given to predict hydrological responses in ungauged catchments and interior catchment points, and also to assess the impact of environmental change on catchment response. This section is therefore focused on reviewing three areas of recent developments in hydrological modelling: predicting hydrological responses in ungauged catchments, predicting responses at interior catchment points using distributed models, and finally assessing the impact of climate and land use change on hydrological prediction.

\subsection{Prediction in Ungauged Basins (PUBs)}

The scientific community has recently focussed substantial attention on ungauged or poorly gauged catchments, since hydrological prediction under these conditions is highly uncertain, but represents the majority of practical applications. The International Association of Hydrological Science (IAHS) initiated the Predictions in Ungauged Basins (PUB) programme as a scientific task for the current decade (2003-2012) to estimate and subsequently reduce predictive uncertainty (Sivapalan, 2003). PUB aspires to constrain the model uncertainty in ungauged catchments through development of improved ways to characterise the effects of heterogeneity, process understanding and through access to new data resources. To achieve this, PUB has been focusing on two research targets: 1) To examine and improve existing models in terms of their ability to predict in ungauged basins through appropriate measures of predictive uncertainty, and 2) To develop new, innovative models to capture space-time variability of hydrological processes for making predictions in ungauged basins, with a concomitant reduction of predictive uncertainty (see details in Sivapalan et al., 2003).

Similarly to the PUB initiative, the Model Parameter Estimation Experiment (MOPEX) has brought about greater focus and coherence to hydrological research and practice. Results from the MOPEX have enhanced scientific insights on predicting hydrological responses in ungauged catchments. MOPEX is an international project led by the National Weather Service (NWS) in USA and aims to develop enhanced techniques for the estimation of parameters in hydrological models in ungauged catchments (Duan et al., 2006). The project's objectives are to develop the necessary data sets from a wide range of climate regimes throughout the world to provide information about ungauged catchment responses, and also to validate a priori parameter estimation methodologies and evaluate potential improvement from model calibration (Huang and Liang, 2006).

Both PUB and MOPEX groups have put substantial focus on model prediction uncertainty, since the latter is amplified when dealing with ungauged or poorly gauged catchments. For instance, imprecisely observed data, inaccuracies in catchment characteristics, imperfect model structures and parameter values could significantly affect the parameter estimation methodologies. However, at present it is arguably impossible to define the nature and extent of all these errors. Finally, as a result of the emphasis on understanding how to transfer information from one location to another and from gauged to ungauged catchment, the scientific initiatives have led to a sharper focus in research and have brought significant advancements and greater coherence in understanding the catchment response (Troch et al., 2008).

\subsection{Distributed hydrological modelling}

The use of distributed models has been encouraged due to the increasing availability of spatially distributed data sets at relatively fine scales (e.g. remote sensed data), information about physical catchment properties at small catchment scale [e.g. the Flood Estimation Handbook and Hydrology of Soil Type datasets (NERC, 1999)], and increasing availability of powerful computer resources. Distributed modelling has usually been driven by raingauge data; however, remote sensed products have been proven as an interesting alternative (Wheater, 2002). This type of data can give good areal estimates of rainfall at fine spatial and temporal resolutions, but lacks the quantitative accuracy of raingauge networks. To overcome this problem, remote sensed data are usually calibrated using point estimates of rainfall made by raingauge networks, as commonly implemented in many national ground-based radar-rainfall systems (Cole and Moore, 2008).

Although the use of distributed models has been encouraged in hydrological applications for many different reasons, e.g. availability of spatial data, and their potential to simulate flow at interior 
catchment points, there are issues that emerge such as scale and parameter estimation (Wooldridge et al., 2001), and calibration strategy (Carpenter and Georgakakos, 2006; Pechlivanidis et al., $2010 b)$. Particularly, as the number of model parameters increases with the degree of spatial discretisation, distributed models can easily become over-parameterised and subsequently ill-posed with respect to the available input-output data. Thus uncertainty in parameter estimates and hence uncertainty in model identification is a common problem (Orlandini and Rosso, 1998; Madsen et al., 2002). In addition, there does not seem to be a clear trend in the literature supporting the superiority of distributed against lumped model spatial resolution in terms of accuracy of predicted flow at the catchment outlet. According to Beven (2009), several sources of uncertainty (i.e. parameter estimation, data uncertainty, model structure identifiability) could contribute to this result.

Several studies have begun to examine the applicability of distributed models and investigate the potential of distributed models against their lumped counterparts. For example, NOAA's National Weather Service (NWS) initiated the Distributed Model Intercomparison Project (DMIP) to compare simulated streamflows from 12 different distributed hydrological models with the lumped Sacramento Soil Moisture Accounting, SAC-SMA model (Smith et al., 2004). The DMIP project aimed to: 1) assess the advantages of applying distributed hydrological models in an operational forecasting environment, 2) assess the importance of spatial rainfall variability on runoff, and 3) evaluate the potential of distributed models to simulate runoff at interior catchment points.

Results show that in cases where a distributed model is more efficient than a lumped model, this seems to be mainly due to the spatial distribution of rainfall, model parameters and channel routing (Ajami et al., 2004). However, it is not clear which factor is generally the most significant, since results depend on catchment hydrological characteristics. In addition, distributed model efficiency seems to depend on rainfall and model spatial resolution. Model performance could be improved when the model can capture the spatial information content of rainfall (e.g. McIntyre and Al-Qurashi, 2009). However, this depends on how much information can be extracted when defining the spatial rainfall pattern (Carpenter and Georgakakos, 2004). Finally, several sources of error/uncertainty such as rainfall, model structure and model parameter uncertainty, should be addressed during robust distributed modelling to improve model performance (Georgakakos et al., 2004). In cases where a lumped model performs better than a distributed model, it has been found this is mainly due to spatial inconsistency of the model parameters (Ajami et al., 2004).

\subsection{Hydrological modelling under environmental change}

One of the main challenges facing hydrological science is to develop a holistic and quantitative understanding of the changing behaviour of hydrological systems. Predictions of hydrological responses need to allow for adaptive temporal evolution of soils, vegetation and climate, while the challenges emerge when extrapolating the model predictions to unmeasured conditions. The two biggest concerns have been the climate change and land use change.

\subsubsection{Climate change}

Global climate change is expected to have a strong impact on water resources on local (Buytaert et al., 2009), regional (Hagemann et al., 2009) and global scales (Alcamo and Henrichs, 2002). Changes in precipitation patterns affect water availability and runoff directly, while changes in temperature, radiation and humidity have an effect on evapotranspiration. As such, the scientific community has been focusing on predicting the potential effects of climate change on the hydrological response (see among others Vicuna and Dracup, 2007; Allen et al., 2010).

Global atmospheric general circulation models (GCMs) have been developed to simulate the present climate and used to predict future climatic change. Although GCMs demonstrate significant skill at the continental and hemispheric spatial scales and incorporate a large proportion of the complexity of the global system, they are inherently unable to represent local subgrid-scale features and dynamics (Fowler et al., 2007). In addition, different GCM datasets produce varying and even contradicting results. Therefore a multi-model ensemble of GCMs is usually used to obtain a reliable impression of the climate change and provide uncertainty information (Sperna Weiland et al., 2010).

To assess the variability in the hydrological response due to climate change, GCM-forced hydrological models are used (Nijssen et al., 2001; Prudhomme and Davies, 2008; Elshamy and Wheater, 2009). Although GCMs can predict variables such as wind, temperature and air pressure 
quite well, precipitation and cloudiness are less well predicted, since these events occur at smaller spatial scale than GCM's grid size (Xu, 1999). To narrow the gap between GCMs ability and hydrological needs, downscaling techniques have been developed to generate high-resolution meteorological inputs (Chun et al., 2009).

The role of hydrological models as part of global climate models has become prominent. The fluxes of moisture and energy from land to atmosphere and from land to oceans, and the impacts of soil moisture on plant cover and $\mathrm{CO}_{2}$ fluxes, are recognised as essential components in global climate models. The need to represent land-atmosphere exchanges in a spatially distributed, continuoustime manner has led to a resurgence of physics-based hydrological models (Scibek et al., 2007). While the motivation for such models is thus clear, the challenges - of identifying model structures and estimating parameters, and conducting uncertainty analysis at realistic computational cost persist (Wilby and Harris, 2006; Serrat-Capdevila et al., 2007).

\subsubsection{Land use change}

Land use and land cover changes are linked to climate change, socio-economic drivers, fires and ecosystem dynamics. Quantification of the effect of land use change on the hydrological response of a catchment has long been an area of interest for the hydrological community, and renewed interest has come from the trend towards integrated management of land and water, together with the prospect of climate change impacts (Wheater and Evans, 2009). Several studies have shown that deforestation, urbanisation and other land use activities can significantly alter the seasonal and annual hydrological response within a catchment (Karvonen et al., 1999), however, distinguishing complex effects of land management change from catchment-scale analysis has proved extremely challenging (Beven et al., 2008). While statistical methods have been able to identify catchmentscale effects of urbanisation (e.g. Institute of Hydrology (1999)), most of the knowledge on the effect of land use change on hydrological response comes from experimental catchment studies, and hydrological modelling (see among others Jackson et al., 2008); however, different results have been obtained, with some even opposing the findings of the others (O'Connell et al., 2004; 2007).

A basic strategy for detection of change is for models to be calibrated to data from a reference period with little change in land use, and then applied to a subsequent period in which changes in land use have been identified (see Schreider et al., 2002). Trend analysis can then be implemented to analyse the bias between modelled and observed data and hence to investigate changes in the hydrological response that might arise due to the identified land use changes (Lorup et al., 1998). However, in practice this is problematic, due to the effects of a heterogeneous mosaic of land use in most catchments, limited information on historical changes in land management practices, and the confounding effects of data noise and climatic variability (Beven et al., 2008). Alternatively, transfer functions approaches have recently been used to empirically identify land use signals when moving from one period to another, and from one catchment to another (e.g. Beven et al., 2008; McIntyre and Marshall, 2010).

Alternatively, various simulation approaches have been considered to assess the impact of land use change using hydrological models. The most rational way is through the implementation of distributed physically-based models in which the land use characteristics are explicitly represented and all the processes influenced by them are modelled using parameters that can physically be estimated a priori (Parkin et al., 1996). However, this approach usually requires spatial data and computational effort, which increases further as the catchment scale increases (Fohrer et al., 2001). One way to address these limitations is the use of detailed physics-based modelling to address local-scale changes, and then the use of 'meta-models' or emulation modelling, to capture the response of detailed models in a simple computationally-efficient formulation for larger scale application (Jackson et al., 2008). Current UK research is also exploring the extent to which, in the absence of local data, surrogate sites can be used to condition physics-based models for upland peatland management (Ballard et al., In Press).

A different approach uses semi-distributed conceptual hydrological models (see among others Brath et al., 2003). Based on this approach, model parameters are estimated a priori based on observed data or modelling experience. However, model calibration still might be needed to adjust some of the parameters. This makes it difficult to associate the calibrated parameters with the land use characteristics, and to quantify uncertainty in simulation results. Alternatively, parameter regionalisation of conceptual hydrological models has been used, in which the impact of land use 
change is estimated by recalculating the model parameters and applying the model to other land use scenarios (De Roo et al., 2001; Wooldridge et al., 2001; Hundecha and Bardossy, 2004). The recalculation of parameters for future conditions is an extension of the ungauged catchment problem, but for non-stationary catchment conditions, and hence recently the applicability of regionalisation methods has been explored to address the land use change problem (Bulygina et al., 2009; In Press).

\section{SUMMARY AND DISCUSSION}

Hydrological models are important for water resources planning, development and management. Their selection is usually based on data availability, spatial representation, computational cost, and model robustness. The current review followed the classification system outlined in Wheater et al. (1993) and classifies hydrological models based on their structure (metric, conceptual, physicsbased, and hybrid), spatial representation (lumped, semi-distributed and distributed), process (deterministic and stochastic), time-scale and space-scale.

Calibration is an integral part of the modelling process, since it is in practice impossible to measure all hydrological properties of a system. In general, model calibration aims to ensure that model components mimic hydrological processes and parameters retain their physical meaning; however results are influenced by multiple sources of uncertainty (uncertainty in the data, model parameters and model structure). The problem of equifinality, where different parameter sets and model structures can yield equally "good" results, poses significant constraints to model development. It is therefore important to develop models that can better exploit the information content of the available data. Wheater (2002) stated that this requires flexible and parsimonious (in terms of number of parameters) model structures that are able to adapt to location specific information content. However, due to data uncertainties, invariably substantial equifinality could remain.

It is broadly recognised that proper quantification and representation of uncertainty in hydrological modelling is essential for decision making; however, there is still the challenge of developing rigorous methods. Sampling based methods such as "classic" Monte Carlo, GLUE and Markov Chain Monte Carlo in theory allow robust analysis of the complexity of a response surface; however, these methods can be prohibitively computationally expensive. GLUE is usually combined with an informal likelihood measure to condition the parameter space while avoiding over-conditioning; attempting to ensure that parameter uncertainty reflects total uncertainty. MCMC is particularly useful where distributions must be partially defined or restricted by output data.

Considering any single source of uncertainty (i.e. structural, parameter, and data errors) may lead to misleading uncertainty predictions in the model output: it is therefore important to consider all types of errors in a comprehensive, explicit and cohesive way to reduce bias and uncertainty in the final prediction. Several frameworks (e.g., among others BATEA, IBUNE, FUSE) have been introduced to assess the impact of data and model structure uncertainty on streamflow simulations; however, further effort to advance scientific understanding is required. According to Liu and Gupta (2007), uncertainty in hydrological predictions could be reduced by: 1) acquiring more informative and higher quality data both in space and time, 2) understanding better the physical processes and improve their representation in the hydrological models, and 3) developing techniques to extract and assimilate information from the available data via the model identification and prediction processes.

Recent research highlights the importance of moving from model calibration to model diagnostic model evaluation to more robustly identify where the model fails and which model aspects need improvement (Gupta et al., 2008). Multi-objective optimisation algorithms highlight trade-offs between different objectives which may be considered as symptoms of model inadequacy and point in the direction of model improvement. Additional reduction of uncertainty in model prediction involves improvement of data quality, and development of approaches that can quantify uncertainty in the various stages of model development.

The scientific community has been focusing on predicting hydrological responses in ungauged or poorly gauged catchments, and interior catchment points. Recent initiatives, such as PUB and MOPEX, have highlighted barriers to prediction at ungauged locations and under environmental change (Troch et al., 2008). Despite the availability of spatial data (e.g. remote sensed data, catchment physical properties), the theoretical potential of distributed models has not been realised. Robust strategies for distributed model calibration and error diagnosis, including the ability to 
account for uncertainty in spatially distributed inputs, and ability to maximise the information content of observed hydrological response, should be developed.

Moreover, prediction under environmental change makes the task of hydrological modelling more challenging. Studies show that the impact of climate and land use change in hydrology could be significant. GCM-forced hydrological models can quantify the potential impact of climate change on the hydrological response; however, approaches for assessment of uncertainty in climate prediction scenarios, as well as in downscaling procedures should be improved. Uncertainty is a key issue affecting the results from land use change studies, related to our limited knowledge of how large scale changes will affect small scale processes, and limited ability to upscale small scale models to more relevant large scale fluxes.

Overall, this paper reviews current methodologies and challenges in hydrological modelling. As a conclusion, we propose that new predictive approaches based on a combination of current and new data assimilation and modelling ideas, using existing and new remote-sensed data sets, are needed.

\section{REFERENCES}

Ajami N.K., Duan Q. and Sorooshian S., (2007), An integrated hydrologic Bayessian multimodel combination framework. Confronting input, parameter, and model structural uncertainty in hydrologic prediction, Water Resources Research, 43(W01403).

Ajami N.K., Gupta H., Wagener T. and Sorooshian S., (2004), Calibration of a semi-distributed hydrologic model for streamflow estimation along a river system, Journal of Hydrology, 298(1-4), 112-135.

Alcamo, J. and Henrics, T., (2002), Critical regions: A model-based estimation of world water resources sensitive to global changes, Aq. Sci., 64, 252-263.

Allen D.M., Cannon A.J., Toews M.W. and Scibek J., (2010), Variability in simulated recharge using different GCMs, Water Resources Research, 46(W00F03).

Arnold J.G., Allen P.M. and Bernhardt G., 1993, A comprehensive surface-groundwater flow model, Journal of Hydrology, 142, 47-69.

Bai Y., Wagener T. and Reed P. (2009), A top-down framework for watershed model evaluation and selection under uncertainty, Environmental Modelling \& Software, 24, 901-915.

Ballard C., McIntyre N., Wheater H.S., Holden J. and Wallage Z.E., Hydrological modelling of drained blanket peatland, Journal of Hydrology, In Press.

Bard Y., (1974), Nonlinear parameter estimation. Academic Press, New York.

Bathurst J.C., Ewen J., Parkin G., O'Connell P.E. and Cooper J.D., (2004), Validation of catchment models for predicting land-use and climate change impacts. 3. Blind validation for internal and outlet responses, Journal of Hydrology, 287(1-4), 74-94.

Beven K., (1993), Prophecy, Reality and Uncertainty in Distributed Hydrological Modeling, Advances in Water Resources, 16(1), 41-51.

Beven K., (2001), Rainfall-Runoff modelling. The Primer. John Wiley and Sons, Chichester, UK, 1-360 pp.

Beven K., (2004), Robert E. Horton's perceptual model of infiltration processes, Hydrological processes, 18, 3447-3460.

Beven K., (2006), A manifesto for the equifinality thesis, Journal of Hydrology, 320(1-2), 18-36.

Beven K.J. and Binley A.M., (1992), The future of distributed models: Model calibration and predictive uncertainty, Hydrological Processes, 6, 279-298.

Beven K. and Freer J., (2001), Equifinality, data assimilation, and uncertainty estimation in mechanistic modelling of complex environmental systems using the GLUE methodology, Journal of Hydrology, 249(1-4), 11-29.

Beven K.J., (2009), Environmental modelling: an uncertain future? Routledge, London, 1-310 pp.

Beven K.J. and Binley A.M., (1992), The future of distributed models: Model calibration and predictive uncertainty, Hydrological Processes, 6, 279-298.

Beven K., Young P., Romanowicz R., O'Connell E., Ewen J., O’Donnell G., Homan I., Posthumus H., Morris J., Hollis J., Rose S., Lamb R. and Archer D., (2008), Analysis of historical data sets to look for impacts of land use and management change on flood generation. Defra R\&D Final Report FD2120. Defra, London.

Boyle D.P., Gupta H.V. and Sorooshian S., (2000), Towards improved calibration of hydrologic models. Combining the strengths of manual and automatic methods, Water Resources Research, 36(12), 3663-3674.

Boyle D.P., Gupta H. V., Sorooshian S., Koren V., Zhang Z. Y. and Smith M., (2001), Toward improved streamflow forecasts: Value of semi distributed modelling, Water Resources Research, 37(11), 27492759. 
Brath A., Montanari A. and Moretti G., (2003), Assessing the effects on flood risk of the land-use changes in the last five decades: an Italian case study, IAHS Publ., 278, 435-441.

Bulygina N. and Gupta H., (2009), Estimating the uncertain mathematical structure of a water balance model via bayesian data assimilation, Water Resources Research, 45(W00B13).

Bulygina N., McIntyre N. and Wheater H., (2009), Conditioning rainfall-runoff model parameters for ungauged catchments and land management impacts analysis, Hydrol. Earth Syst. Sci. 13(6), 893904.

Bulygina N., Mclntyre N. and Wheater $\mathrm{H}$., Bayesian conditioning of a rainfall-runoff model for predicting flows in ungauged catchments and under land use changes, Water Resources Research, In Press.

Butts M.B., Payne J.T., Kristensen M. and Madsen H., (2004), An evaluation of the impact of model structure on hydrological modelling uncertainty for streamflow simulation, Journal of Hydrology, 298(1-4), 242-266.

Buytaert W., Celleri R. and Timbe L., (2009), Predicting climate change impacts on water resources in the tropical Andes: the effects of GCM uncertainty, Geophysical Research Letters, 36(L07406).

Carpenter T.M. and Georgakakos K.P., (2004), Impacts of parametric and radar rainfall uncertainty on the ensemble streamflow simulations of a distributed hydrologic model, Journal of Hydrology, 298(1-4), 202-221.

Carpenter T.M. and Georgakakos K.P., (2006), Intercomparison of lumped versus distributed hydrologic model ensemble simulations on operational forecast scales, Journal of Hydrology, 329(1-2), 174-185.

Chun K.P., Wheater H.S. and Onof C.J., (2009), Streamflow estimation for six UK catchments under future climate scenarios, Hydrology Research, 40, 96-112.

Clark M.P., Slater A. G., Rupp D. E., Woods R. A., Vrugt J. A., Gupta H. V., Wagener T. and Hay L. E., (2008), Framework for Understanding Structural Errors (FUSE): A modular framework to diagnose differences between hydrological models, Water Resources Research, 44(W00B02).

Cole S.J. and Moore R.J., (2008), Hydrological modelling using raingauge- and radar-based estimators of areal rainfall, Journal of Hydrology, 358(3-4), 159-181.

Croke B.F.W., (2007), The role of uncertainty in design of objective functions, MODSIM 2007 International Congress on Modelling and Simulation. Modelling and Simulation Society of Australia and New Zealand. Modelling and Simulation Society of Australia and New Zealand, New Zealand, pp. 2541-2547.

Dawson C.W., Abrahart R.J., Shamseldin A.Y. and Wilby R.L., (2006), Flood estimation at ungauged sites using artificial neural networks, Journal of Hydrology, 319(1-4), 391-409.

De Roo A., Odijk M., Schmuck G., Koster E. and Lucieer A., (2001), Assessing the effects of land use changes in the Meuse and Oder Catchment, Phys. Chem. Earth (B), 26, 593-599.

Dodov B. and Foufoula-Georgiou E., (2005), Incorporating the spatio-temporal distribution of rainfall and basin geomorphology into nonlinear analyses of streamflow dynamics, Advances in Water Resources, 28(7), 711-728.

Duan Q., Gupta V.K. and Sorooshian S., (1993), A shuffled complex evolution approach for effective and efficient global minimization, Journal of Optimization Theory and Applications, 76(3), 501-521.

Duan Q., Schaake J., Andreassian V., Franks S., Goteti G., Gupta H.V., Gusev Y. M., Habets F., Hall A., and Hay L., (2006), Model Parameter Estimation Experiment (MOPEX): An overview of science strategy and major results from the second and third workshops, Journal of Hydrology, 320(1-2), 3-17.

Dunn S.M., Freer J., Weiler M., Kirkby M. J., Seibert J., Quinn P.F., Lischeid G., Tetzlaff D. and Soulsby C., (2008), Conceptualization in catchment modelling: simply learning?, Hydrological Processes, 22(13), 2389-2393.

Elshamy M.E. and Wheater H.S., (2009), Performance assessment of a GCM land surface scheme using a fine-scale calibrated hydrological model: an evaluation of MOSES for the Nile Basin, Hydrological Processes, 23, 1548-1564.

Ewen J. and Parkin G., (1996), Validation of catchment models for predicting land-use and climate change impacts. 1. Method, Journal of Hydrology, 175, 583-594.

Fenicia F., Savenije H.H.G., Matgen P. and Pfister L., (2008), Understanding catchment behavior through stepwise model concept improvement, Water Resources Research, 44(W01402).

Fohrer N., Haverkamp S., Eckhardt K. and Frede H.G., (2001), Hydrologic response to land use changes on the catchment scale, Phys. Chem. Earth (B), 26, 577-582.

Fowler H.J., Blenkinsop S. and Tebaldi C., (2007), Linking climate change modelling to impacts studies: recent advances in downscaling techniques for hydrological modelling, International Journal of Climatology, 27, 1547-1578.

Freer J., Beven K. and Ambroise B., (1996), Bayesian estimation of uncertainty in runoff prediction and the value of data: An application of the GLUE approach, Water Resources Research, 32(7), 21612174. 
Freer J.E., McMillan H., McDonnell J.J. and Beven K.J., (2004), Constraining dynamic TOPMODEL responses for imprecise water table information using fuzzy rule based performance measures, Journal of Hydrology, 291(3-4), 254-277.

Georgakakos K.P., Seo D.J., Gupta H., Schaake J. and Butts M.B., (2004), Towards the characterization of streamflow simulation uncertainty through multimodel ensembles, Journal of Hydrology, 298(1-4), 222-241.

Gotzinger J. and Bardossy A., (2008), Generic error model for calibration and uncertainty estimation of hydrological models, Water Resources Research, 44(W00B07).

Gourley J.J. and Vieux B.E., (2006), A method for identifying sources of model uncertainty in rainfallrunoff simulations, Journal of Hydrology, 327(1-2), 68-80.

Green W.H. and Ampt G., (1911), Studies on soil physics, 1. The flow of air and water through soils, J. Agric. Sci., 4(1), 1-24.

Guo J., Liang X. and Ruby Leung L., (2004), Impacts of different precipitation data sources on water budgets, Journal of Hydrology, 298(1-4), 311-334.

Gupta H.V., Beven K. and Wagener T., (2005), Model calibration and uncertainty estimation, Encyclopedia of Hydrological Sciences, 11(131), 1-17.

Gupta H.V., Kling H., Yilmaz K.K. and Martinez G.F., (2009), Decomposition of the mean squared error and NSE performance criteria: Implications for improving hydrological modelling, Journal of Hydrology, 377(1-2), 80-91.

Gupta H.V., Sorooshian S. and Yapo P.O., (1998), Towards improved calibration of hydrologic models: Multiple and noncommensurable measures of information, Water Resources Research, 34(4), 751763.

Gupta H., Wagener T. and Liu Y., (2008), Reconciling theory with observations: elements of a diagnostic approach to model evaluation, Hydrological Processes, 22(18), 3802-3813.

Hagemann S., Gottel H., Jacob D., Lorenz P. and Roeckner E., (2009), Improved regional scale processes reflected in projected hydrological changes over large European catchments, Clim. Dynam., 32, 767-781.

Hallett S.H., Bullock P. and Baillie I., (2006), Towards a World Soil Survey Archive and Catalogue, Soil Use and Management, 22(2), 227-228.

Hastings W.K., (1970), Monte Carlo sampling methods using Markov chains and their applications, Biometrika, 57, 97-109.

Helton J. and Davis F., (2002), Illustration of sampling-based methods for uncertainty and sensitivity analysis, Risk Analysis, 22, 622-691.

Helton J. and Davis F., (2003), Latin hypercube sampling and the propagation of uncertainty in analyses of complex systems, Reliability Engineering and Systems Safety, 81, 23-69.

Hornberger G. and Spear R., (1981), An approach to the preliminary analysis of environmental systems, Journal of Environmental Management, 12, 7-18.

Huang M. and Liang X., (2006), On the assessment of the impact of reducing parameters and identification of parameter uncertainties for a hydrologic model with applications to ungauged basins, Journal of Hydrology, 320(1-2), 37-61.

Hundecha Y. and Bardossy A., (2004), Modeling of the effect of land use changes on the runoff generation of a river basin through parameter regionalization of a watershed model, Journal of Hydrology, 292(1-4), 281-295.

Institute of Hydrology, (1999), Flood Estimation Handbook. Institute of Hydrology, Crowmarsh Gifford, UK.

Isukapalli, S.S., (1999), Uncertainty analysis of transport-transformation models, Ph.D. thesis, Rutgers University, New Jersey.

Jackson B.M., (2007), Modelling water and solute transport within vegetated soils using a stochastic framework. PhD Dissertation Thesis, Department of Civil and Environmental Engineering, Imperial College London, 1-386 pp.

Jackson B.M., Wheater H.S., Mcintyre N.R., Chell J., Francis O.J., Frogbrook Z., Marshall M., Reynolds B. and Solloway I., (2008), The impact of upland land management on flooding: insights from a multiscale experimental and modelling programme, Journal of Flood Risk Management, 1, 71-80.

Jain A., Sudheer K.P. and Srinivasulu S., (2004), Identification of physical processes inherent in artificial neural network rainfall runoff models, Hydrological Processes 18, 571-583.

Karvonen T., Koivusalo H., Jauhiainen M., Palko J. and Weppling K., (1999), A hydrological model for predicting runoff from different land use areas, Journal of Hydrology, 217, 253-265.

Kavetski D. and Clark M., (2010a), Ancient numerical daemons of conceptual hydrological modelling: 2. Impact of time stepping schemes on model analysis and prediction, Water Resources Research, 46(W10511). 
Kavetski D. and Clark M., (2010b), Numerical troubles in conceptual hydrology: Approximations, absurdities and impact of hypothesis testing, Hydrological Processes, 25(4), 661-670.

Kavetski D., Kuczera G. and Franks S.W., (2006), Bayesian analysis of input uncertainty in hydrological modeling: 2. Application, Water Resources Research, 42(W03408).

Klemes V., (1986), Operational testing of hydrological simulation models, Hydrological Sciences Journal, 31(1), 13-24.

Koren V., Moreda F. and Smith M., (2008), Use of soil moisture observations to improve parameter consistency in watershed calibration, Physics and Chemistry of the Earth, 33(17-18), 1068-1080.

Kuczera G. and Parent E., (1998), Monte Carlo assessment of parameter uncertainty in conceptual catchment models: the Metropolis algorithm, Journal of Hydrology, 211(1-4), 69-85.

Lange N., (1999), New mathematical approaches in hydrological modelling. An application of Artificial Neural Networks, Physics and Chemistry of the Earth, 24(1), 31-35.

Lee H., McIntyre N., Wheater H. and Young A., (2005), Selection of conceptual models for regionalisation of the rainfall-runoff relationship, Journal of Hydrology, 312(1-4), 125-147.

Lees M., (2000), Data-based mechanistic modelling and forecasting of hydrological systems, Journal of Hydroinformatics, 2(1),15-34.

Lekkas D., (2008), Using complementary methods for improved flow forecasting, Hydrological Sciences Journal, 53(4), 696-705.

Lekkas D. and Onof C., (2006), Introducing the variation of advective time delay (ATD) to transfer function models, Environmental Modelling \& Software, 21(8), 1180-1189.

Liu Y., Freer J., Beven K. and Matgen P., (2009), Towards a limits of acceptability approach to the calibration of hydrological models: Extending observation error, Journal of Hydrology, 367(1-2), 93103.

Liu Y. and Gupta H.V., (2007), Uncertainty in hydrologic modeling: Toward an integrated data assimilation framework, Water Resources Research, 43(W07401).

Lorup J.K., Refsgaard J.C. and Mazvimavi D., (1998), Assessing the effect of land use change on catchment runoff by combined use of statistical tests and hydrological modelling: case studies from Zimbabwe, Journal of Hydrology, 205, 147-163.

Madsen H., Wilson G. and Ammentorp H.C., (2002), Comparison of different automated strategies for calibration of rainfall-runoff models, Journal of Hydrology, 261(1-4), 48-59.

Mantovan P. and Todini E., (2006), Hydrological forecasting uncertainty assessment: Incoherence of the GLUE methodology, Journal of Hydrology, 330(1-2), 368-381.

Matott L.S., Babendreier J.E. and Purucker S.T., (2009), Evaluating uncertainty in integrated environmental models: A review of concepts and tools, Water Resources Research, 45(W06421).

McIntyre N., Wheater H. and Lees M., (2002) Estimation and propagation of parametric uncertainty in environmental models, Journal of Hydroinformatics, 4(3), 177-198.

McIntyre N., Young P.C., Orellana B., Marshall M., Reynolds B. and Wheater H.S., Identification of nonlinearity in rainfall-flow response using data-based mechanistic modelling, Water Resources Research, In Press.

McIntyre N. and Marshall M., (2010), Identification of rural land management signals in runoff response, Hydrological Processes, 24(24), 3521-3534.

Mclntyre N. and Al-Qurashi A., (2009), Performance of ten rainfall-runoff models applied to an arid catchment in Oman, Environmental Modelling \& Software, 24(6), 726-738.

McIntyre N., Jackson B., Wade A.J., Butterfield D. and Wheater H., (2005a), Sensitivity analysis of a catchment-scale nitrogen model, Journal of Hydrology, 315, 71-92.

McIntyre N., Lee H., Wheater H., Young A. and Wagener T., (2005b), Ensemble predictions of runoff in ungauged catchments, Water Resources Research, 41(W12434).

Mein R.G. and Larson C.L., (1973), Modeling infiltration during a steady rain, Water Recourses Research, 9(2), 384-394.

Melching C.S. and Singh V.P., (1995), Reliability estimation, Computer models of watershed hydrology, Water Resources Publications, USA.

Moore C. and Doherty J., (2005), Role of the calibration process in reducing model predictive error, Water Resources Research, 41(W05020).

Moradkhani H., Sorooshian S., Gupta H.V., Houser P., (2005), Dual state parameter estimation of hydrologic models using ensemble Kalman filter, Advances in Water Resources, 28, 135-147.

Nash J.E. and Sutcliffe J.V., (1970), River flow forecasting through conceptual models, Journal of Hydrology, 10, 282-290.

NERC, (1975), Flood Studies Report. Natural Environmental Research Council, London, UK (5 volumes).

NERC, (1999), Natural Environmental Research Council, Wallingford, UK. (http://soilbio. nerc.ac.uk/datapolicy and strategy.htm). 
Neuman S.P., (2003), Maximum likelihood Bayesian averaging of uncertain model predictions, Stochastic Environmental Research and Risk Assessment, 17, 291-305.

Nijssen B., O'Donnel G.M. and Lettenmaier D.P., (2001), Predicting the discharge of global rivers, Am. Meteorol. Soc., 3307-3323.

O'Connell P.E., Beven K.J., Carney J.N., Clements R.O., Ewen J., Fowler H., Harris G.L., Hollis J., Morris J., O'Donnell G.M., Packman J.C., Parkin A., Quinn P.F., Rose S.C., Shepherd M. and Tellier S., (2004), Review of impacts of rural land use and management on flood generation. Part A: Impact Study Report. R\&D Technical Report FD2114/TR, DEFRA, London, UK, 142pp.

O'Connell P.E., Ewen J., O'Donnell G. and Quinn P., (2007), Is there a link between agricultural land usemanagement and flooding?, Hydrology and Earth System Sciences, 11, 96-107.

Orellana B., Pechlivanidis I.G., McIntyre N., Wheater H.S. and Wagener T., (2008), A toolbox for the identification of parsimonious semi-distributed rainfall-runoff models: Application to the Upper Lee catchment, in iEMSs 2008: International Congress on Environmental Modelling and Software, 1, 670677, 7-10 July, Barcelona, Spain.

Orlandini S. and Rosso R., (1998), Parameterization of stream channel geometry and the distributed modeling of catchment dynamics, Water Resources Research, 103, 1971-1986.

Oudin L., Perrin C., Mathevet T., Andreassian V. and Michel C., (2006), Impact of biased and randomly corrupted inputs on the efficiency and the parameters of watershed models, Journal of Hydrology, 320(1-2), 62-83.

Parkin G., O'Donnell G., Ewen J., Bathurst J.C., O'Connell P.E. and Lavabre J., (1996), Validation of catchment models for predicting land-use and climate change impacts. 1 . Case study for a Mediterranean catchment, Journal of Hydrology, 175, 595-613.

Pechlivanidis I.G., McIntyre N. and Wheater H.S., (2008), The significance of spatial variability of rainfall on runoff, in iEMSs 2008: International Congress on Environmental Modelling and Software, 1, 478485, 7-10 July, Barcelona, Spain.

Pechlivanidis I.G., Jackson B., McMillan H., (2010a), The use of entropy as a model diagnostic in rainfallrunoff modelling, in iEMSs 2010: International Congress on Environmental Modelling and Software, 58 July, Ottawa, Canada.

Pechlivanidis I.G., McIntyre N.R. and Wheater H.S., (2010b), Calibration of the semi-distributed PDM rainfall-runoff model in the Upper Lee catchment, UK, Journal of Hydrology, 386(1-4), 198-209.

Perrin C., Michel C. and Andreassian V., (2001), Does a large number of parameters enhance model performance? Comparative assessment of common catchment model structures on 429 catchments, Journal of Hydrology, 242(3-4), 275-301.

Prudhomme C. and Davies H., (2008), Assessing uncertainties in climate change impact analyses on the river flow regimes in the UK. Part 2: Future climate, Climatic Change, 93, 197-222.

Ratto M., Tarantola S. and Saltelli A., (2001), Sensitivity analysis in model calibration: GSA-GLUE approach, Computer Physics Communications, 136, 212-224.

Ratto M., Young P.C., Romanowicz R., Pappenberger F., Saltelli A. and Pagano A., (2007), Uncertainty, sensitivity analysis and the role of data based mechanistic modelling in hydrology, Hydrology and Earth System Sciences, 11, 1249-1266.

Saltelli A., (2002), Making best use of model evaluations to compute sensitivity indices, Computer Physics Communications, 145, 280-297.

Schaefli B. and Gupta H., (2007), Do Nash values have value?, Hydrological Processes, 21: $2075-2080$.

Schreider S.Y., Jakeman A.J., Letcher R.A., Nathan R.J., Neal B.P., and Beavis S.G., (2002), Detecting changes in streamflow response to changes in non-climatic catchment conditions: farm dam development in the Murray-Darling basin, Aust. J. Hydrol., 262, 84-98.

Scibek J., Allen D.M., Cannon A. and Whitfield P., (2007), Groundwater-surface water interaction under scenarios of climate change using a high-resolution transient groundwater model, Journal of Hydrology, 333, 165-181.

Serrat-Capdevila A., Valdes J.B., Perez J.G., Baird K., Mata L.J. and Maddock T., (2007), Modeling climate change impacts - and uncertainty - on the hydrology of a riparian system: The San Pedro Basin (Arizona/Sonora), Journal of Hydrology, 347, 48-66.

Sherman L.K., (1932), Stream flow from rainfall by the unit-graph method, Engineering News Record, 108, 501-505.

Singh V.P., (1995), Computer models of watershed hydrology, Water Resources Publications, LLC, USA.

Singh V.P., (1997), Effect of spatial and temporal variability in rainfall and watershed characteristics on stream flow hydrograph, Hydrological Processes, 11(12), 1649-1669.

Singh V.P. and Frevert D., (2006), Watershed models. Boca Raton, Taylor \& Francis.

Singh V.P. and Woolhiser D.A., (2002), Mathematical modeling of watershed hydrology, Journal of Hydrologic Engineering, 7(4), 270-292. 
Sivapalan M. (2003), Prediction in ungauged basins: a grand challenge for theoretical hydrology, Hydrological Processes, 17(15), 3163-3170.

Sivapalan M., Takeuchi K., Franks S., Gupta V., Karambiri H., Lakshmi V., Liang X., McDonnell J., Mendiondo E., O'Connell P., Oki T., Pomeroy J., Schertzer D., Uhlenbrook S. and Zehe E. (2003), IAHS Decade on Predictions in Ungauged basins (PUB), 2003-2012: Shaping an exciting future for the hydrological sciences, Hydrological Sciences Journal, 48(6), 867-880.

Smith M.B., Seo D.J., Koren V.I., Reed S.M., Zhang Z., Duan Q., Moreda F., and Cong S., (2004), The distributed model intercomparison project (DMIP): motivation and experiment design, Journal of Hydrology, 298(1-4), 4-26.

Smith P.J., Beven K.J. and Tawn J.A., (2008), Detection of structural inadequacy in process-based hydrological models: A particle-filtering approach, Water Resources Research, 44(W01410).

Sorooshian S. and Dracup J.A., (1980), Stochastic parameter estimation procedures for hydrologic rainfall-runoff models - correlated and heteroscedastic error cases, Water Resources Research, 16(2), 430-442.

Sorooshian S. and Gupta V.K., (1995), Model Calibration, Computer models of watershed hydrology, edited by Singh, V.P., Water Resources Publications, USA.

Sperna Weiland F.C., van Beek L.P.H., Kwadijk J.C.J. and Bierkens M.F.P., (2010), The ability of a GCMforced hydrological model to reproduce global discharge variability, Hydrol. Earth Syst. Sci., 14, 15951621.

Stephenson G.R. and Freeze R.A., (1974), Mathematical simulation of subsurface flow contributions to snowmelt runoff, Reynolds Creek watershed, Idaho, Water Resources Research, 10, 284-294.

Tang Y., Reed P., Wagener T. and van Werkhoven K., (2007), Comparing sensitivity analysis methods to advance lumped watershed model identification and evaluation, Hydrology and Earth System Sciences, 11(2), 793-817.

Troch P.A., Carrillo G.A., Heidbuechel I., Rajagopal S., Switanek M., Volkmann T.H.M. and Yaeger M.A., (2008), Dealing with landscape heterogeneity in watershed hydrology: A review of recent progress toward new hydrological theory, Geography Compass, 3(1), 375-392.

van Werkhoven K., Wagener T., Reed P. and Tang Y., (2009), Sensitivity-guided reduction of parametric dimensionality for multi-objective calibration of watershed models, Advances in Water Resources, 32(8), 1154-1169.

Vicuna S. and Dracup J.A., (2007), The evolution of climate change impact studies on hydrology and water resources in California, Climate Change, 82(3-4), 327-350.

Vrugt J.A., Diks C.G.H., Gupta H.V., Bouten W. and Verstraten J.M., (2005), Improved treatment of uncertainty in hydrologic modeling: Combining the strengths of global optimization and data assimilation, Water Resources Research, 41(W01017).

Vrugt J.A., Gupta H.V., Bastidas L.A., Bouten W. and Sorooshian S., (2003), Effective and efficient algorithm for multiobjective optimization of hydrologic models, Water Resources Research, 39(8), 1214.

Vrugt J.A. and Robinson B.A., (2007), Treatment of uncertainty using ensemble methods: Comparison of sequential data assimilation and Bayesian model averaging, Water Resources Research, 43(W01411).

Vrugt J.A., Robinson B.A. and Hyman J.M., (2008a), Self-adaptive multimethod search for global optimization in real-parameter spaces, IEEE Transactions on Evolutionary Computation, 13(2), 1-17.

Vrugt J.A., ter Braak C.J.F., Clark M.P., Hyman J.M. and Robinson B.A., (2008b), Treatment of input uncertainty in hydrologic modeling: Doing hydrology backward with Markov chain Monte Carlo simulation, Water Resources Research, 44(W00B09).

Vrugt J.A., ter Braak C.J.F., Diks C.G.H., Robinson B.A., Hyman J.M. and Higdon D., (2009), Accelerating Markov Chain Monte Carlo simulation by differential evolution with self-adaptive randomized subspace sampling, Journal of Nonlinear Sciences and Numerical Simulation, 10(3), 273290.

Vrugt J.A., ter Braak C.J.F., Gupta H.V. and Robinson B.A., (2008c), Equifinality of formal (DREAM) and informal (GLUE) Bayesian approaches in hydrologic modeling?, Stochastic Environmental Research and Risk Assessment, 23(7), 1011-1026.

Wagener T., (2007), Can we model the hydrological impacts of environmental change?, Hydrological Processes, 21, 3233-3236.

Wagener T. and Kollat J., (2007), Numerical and visual evaluation of hydrological and environmental models using the Monte Carlo analysis toolbox, Environmental Modelling \& Software, 22(7), 10211033. 
Wagener T., McIntyre N., Lees M., Wheater H. and Gupta H., (2003), Towards reduced uncertainty in conceptual rainfall-runoff modeling: dynamic identifiability analysis, Hydrological Processes, 17(2), 455-476.

Wagener T., Sivapalan M., Troch P. and Woods R., (2007), Catchment classification and hydrologic similarity, Geography Compass, 1(4), 901-931.

Wagener T., Wheater H.S. and Gupta H.V., (2004), Rainfall-Runoff Modelling in Gauged and Ungauged Catchments. Imperial College Press, London, UK, 1-306 pp.

Wheater H.S., (2002), Progress in and prospects for fluvial flood modelling. 360 (1796), Philosophical Transactions of the Royal Society of London, Series A-Mathematical Physical and Engineering Sciences.

Wheater H.S. and Evans E.P., (2009), Land use, water management and future flood risk, Land Use Policy, 26S, S251-S264.

Wheater H.S., Jakeman A.J., Beven K.J., Beck M.B. and McAleer M.J., (1993), Progress and directions in rainfall-runoff modelling, Modelling change in environmental systems, New York, pp. 101-132.

Wilby R.L. and Harris I., (2006), A framework for assessing uncertainties in climate change impacts: Lowflow scenarios for the River Thames, UK, Water Resources Research, 42(W02419).

Wooldridge S., Kalma J. and Kuczera G., (2001), Parameterisation of a simple semi-distributed model for assessing the impact of land-use on hydrologic response, Journal of Hydrology, 254(1-4), 16-32.

Xu C.Y., 1999. Climate change and hydrologic models: A review of existing gaps and recent research developments, Water Resources Management, 13, 369-382.

Yapo P.O., Gupta H.V. and Sorooshian S., (1998), Multi-objective global optimization for hydrologic models, Journal of Hydrology, 204(1-4), 83-97.

Young A.R., Keller V. and Griffith J., (2006), Predicting low flows in ungauged basins: a hydrological response unit approach to continuous simulation, Climate Variability and Change - Hydrological Impacts. IAHS Press, Havana, Cuba, pp. 134-138.

Young P.C., (1999), Data-based mechanistic modelling, generalised sensitivity and dominant mode analysis, Computer Physics Communications, 115, 1-17.

Young P.C., (2003), Top-down and data-based mechanistic modelling of rainfall-flow dynamics at the catchment scale, Hydrological Processes, 17(11), 2195-2217.

Young P.C., (2005), Rainfall-runoff modelling: Transfer Function Models, Encyclopedia of Hydrological Sciences, 11(1), 1-16.

Young P.C., Jakeman A.J. and Post D.A., (1997), Recent advances in the data-based modelling and analysis of hydrological systems, Water Science and Technology, 36(1), 99-116. 